Check for updates

Cite this: RSC Adv., 2018, 8, 23599

\title{
Fabrication of nitrogen-doped ZnO nanorod arrays by hydrothermal synthesis and ambient annealing $\dagger$
}

\author{
Ryosuke Kobayashi, (D) a Tetsuo Kishi, (D) a Yuta Katayanagi, (DD ${ }^{\mathrm{b}}$ Tetsuji Yano ${ }^{\mathrm{a}}$ \\ and Nobuhiro Matsushita (D) *a
}

Nitrogen-doped $\mathrm{ZnO}$ nanorod arrays ( $\mathrm{N}: \mathrm{ZnO}$ NRAs) were fabricated by hydrothermal synthesis using a zinc-ammine complex solution, followed by annealing at elevated temperatures under ambient conditions. After annealing at $400{ }^{\circ} \mathrm{C}$ for $1 \mathrm{~h}$, Raman spectra indicated that nitrogen was incorporated in the $\mathrm{ZnO}$ crystal structure. $\mathrm{NH}_{3}$-ligands in the zinc-ammine complex precursor were incorporated in ZnO crystals during hydrothermal crystal growth and were then ruptured during annealing. Photoluminescence spectra indicated that during post-annealing, the nitrogen was incorporated into the oxygen site, which created accompanying defects such as oxygen vacancies and/or interstitial oxygen. The absorption edge in diffuse-reflectance UV-visible spectra revealed visible absorption after postannealing. In addition, the $\mathrm{N}: \mathrm{ZnO}$ NRAs generated strong visible-light-induced photocurrents. Nitrogen doping caused a decline in carrier density, as confirmed by an electrochemical Mott-Schottky plot. These results suggest that this cost-effective fabrication has many potential applications such as solarinduced water splitting.

Received 16th May 2018

Accepted 18th June 2018

DOI: $10.1039 / \mathrm{c} 8 \mathrm{ra04168g}$

rsc.li/rsc-advances processes are much easier for fabricating undoped $\mathrm{ZnO}$ NRAs, ${ }^{17,18}$ and offer cost-efficiency and the potential for largescale production. Generally, wet fabrication of N:ZnO NRAs requires two steps: a solution process, followed by post-doping via annealing in an ammonia gas atmosphere. ${ }^{\mathbf{1 4}}$ Alternatively, ion implantation ${ }^{19}$ is used to incorporate nitrogen without changing the nanostructure. However, the dopant distribution within the crystal cannot be effectively controlled with annealing in ammonia gas, ${ }^{\mathbf{2 0}, 21}$ and complex, expensive systems are required for ion implantation. ${ }^{19}$ It is thus desirable to establish an easy, cost-effective method to fabricate uniformly nitrogendoped $\mathrm{N}: Z n O$ NRAs.

Here, N:ZnO NRAs were fabricated by combining hydrothermal synthesis using a zinc-ammine complex solution, and post-annealing in an ambient atmosphere. The zinc-ammine complex solution was chosen as a precursor for the hydrothermal synthesis because it provided nitrogen sources via the $\mathrm{NH}_{3}$ ligands. The process was simple, and did not require specialized equipment or conditions. N:ZnO NRAs were obtained by annealing as-grown samples above $400{ }^{\circ} \mathrm{C}$; visible light photocurrents were maximized when the sample was annealed at $500{ }^{\circ} \mathrm{C}$. The nitrogen doping mechanism was as follows: (1) $\mathrm{NH}_{3}$ ligands in the zinc-ammine complex were incorporated in $\mathrm{ZnO}$ crystals during the hydrothermal crystal growth; (2) the ligands dissociated during annealing; and (3) nitrogen doping occurred within the $\mathrm{ZnO}$ crystals. Defect formation mechanisms followed by annealing were also investigated.

\footnotetext{
${ }^{a}$ Department of Materials Science and Engineering, School of Materials and Chemical Technology, Tokyo Institute of Technology, 2-12-1 Ookayama, Meguro-ku, Tokyo 152-8550, Japan. E-mail: matsushita.n.ab@m.titech.ac.jp; Fax: +81-3-5734-3353; Tel: $+81-3-5734-2875$

${ }^{b}$ Department of Technology Education, Faculty of Education, Gunma University, 4-2 Aramaki-machi, Maebashi, Gunma 371-8510, Japan

$\dagger$ Electronic supplementary information (ESI) available. See DOI: $10.1039 / \mathrm{c} 8 \mathrm{ra} 04168 \mathrm{~g}$
} 


\section{Experimental}

Preparation of zinc-ammine complex solution

$\mathrm{Zn}\left(\mathrm{NO}_{3}\right)_{2} \cdot 6 \mathrm{H}_{2} \mathrm{O}(>99 \%), \mathrm{NaOH}(>97 \%)$, and $\mathrm{NH}_{3}$ aqueous solution (28\%), all from Wako Pure Chemical Industries, Ltd., Japan, were used without further purification. A zinc-ammine complex precursor solution was prepared according to Meyers et al. ${ }^{22}$ Specifically, $10 \mathrm{ml}$ of aqueous $2.5 \mathrm{M} \mathrm{NaOH}$ was added dropwise to $15 \mathrm{ml}$ of aqueous $0.5 \mathrm{M} \mathrm{Zn}\left(\mathrm{NO}_{3}\right)_{2} \cdot 6 \mathrm{H}_{2} \mathrm{O}$ under vigorous stirring. The resulting slurry was centrifuged and the supernatant was removed. Rinsing and centrifugation was performed four times to remove $\mathrm{Na}^{+}$and $\mathrm{NO}_{3}{ }^{-}$. The precipitate was then dissolved in $50 \mathrm{ml}$ of aqueous 6.6 $\mathrm{M} \mathrm{NH}_{3}$ to yield the zinc-ammine complex solution.

\section{Preparation of $\mathrm{ZnO}$ seed layer}

ZnO seed layers were deposited on a $20 \mathrm{~mm} \times 30 \mathrm{~mm}$ FTO glass substrate (Sigma Aldrich, $\sim 7 \Omega \mathrm{sq}^{-1}$ ) by spin-coating the zincammine complex solution. The substrate was first ultrasonically cleaned in acetone, then ethanol, and finally in distilled water for 10 min each. Then, the substrate was exposed to UV-ozone (ProCleaner ${ }^{\mathrm{TM}}$ Plus, Bioforce Nanosciences) for $10 \mathrm{~min}$ to produce a hydrophilic surface. The spin-coating was performed at $3000 \mathrm{rpm}$ for $30 \mathrm{~s}$. The substrate was then heated on a hot plate at $150{ }^{\circ} \mathrm{C}$ for $5 \mathrm{~min}$. The spin-coating and heating steps were repeated ten times to get the desired $\mathrm{ZnO}$ thickness.

\section{Fabrication of N-doped ZnO nanorod arrays}

The zinc-ammine complex solution was diluted by a factor of three with distilled water to form a growth solution. The substrate was placed in a Teflon vessel and $30 \mathrm{ml}$ of the growth solution was added. The vessel was covered, tightly enclosed in a stainless autoclave, and placed in an oven. The hydrothermal reaction was performed at $100{ }^{\circ} \mathrm{C}$ for $24 \mathrm{~h}$. The substrates were then removed and immediately rinsed with distilled water. Then the samples were dried in an oven at $100{ }^{\circ} \mathrm{C}$ for $10 \mathrm{~min}$, and annealed at $300-700{ }^{\circ} \mathrm{C}$ with a programming rate of $10{ }^{\circ} \mathrm{C} \mathrm{min}{ }^{-1}$.

\section{Characterization}

Crystal phases were determined by X-ray diffraction (XRD), (Bruker D8, Bruker), using $\mathrm{Cu} \mathrm{K} \alpha$ radiation. Sample morphologies were imaged with field-emission scanning electron microscopy (FE-SEM) (S-4500, Hitachi). Diffuse reflectance spectra were recorded with a UV-vis spectrophotometer (V-670, JASCO), using $\mathrm{BaSO}_{4}$ as a reference material. Raman spectra were recorded with a Nanofinder30 spectrometer, using $532 \mathrm{~nm}$ excitation from a Nd:YAG laser. Photoluminescence (PL) spectra were recorded at room temperature with $325 \mathrm{~nm}$ excitation from a He-Cd laser. X-ray photoelectron spectroscopy (XPS) spectra were recorded on a Perkin-Elmer model 5500 MT XPS system, using monochromatic $\mathrm{Al} \mathrm{K} \alpha$ radiation. Binding energies were calibrated with respect to the $\mathrm{C} 1 \mathrm{~s}$ core level at $284.8 \mathrm{eV}$.

\section{Photoelectrochemical experiments}

Photoelectrochemical characteristics were measured with a potentiostat (HZ-7000, Hokuto Denko), using a standard three-electrode cell under visible light irradiation from a $100 \mathrm{~W}$ xenon lamp equipped with a $<422 \mathrm{~nm}$ cutoff filter (Asahi Spectra). N:ZnO NRAs on FTO substrates were used as working electrodes with an effective area of $4 \mathrm{~cm}^{2}$. A Pt plate and an $\mathrm{Ag} / \mathrm{AgCl}$ electrode were used as counter and reference electrodes, respectively. A $0.1 \mathrm{M}$ $\mathrm{Na}_{2} \mathrm{SO}_{4}$ aqueous solution was used as the electrolyte and was purged with Ar bubbling for $30 \mathrm{~min}$ before the experiments. Electrochemical impedance spectroscopy (EIS) was performed in a $0.5 \mathrm{M} \mathrm{Na}_{2} \mathrm{SO}_{4}$ electrolyte solution with a $5 \mathrm{mV}$ amplitude, a 20 $\mathrm{kHz}$ to $1 \mathrm{~Hz}$ frequency range, and a potential range of -0.6 to $1.0 \mathrm{~V}$ vs. Ag/AgCl. Experimental setups are shown in Fig. S1. $\dagger$

\section{Results and discussion}

Fig. 1 shows the XRD patterns of as-grown N:ZnO NRAs and those annealed at $500{ }^{\circ} \mathrm{C}$ for $1 \mathrm{~h}$. The peaks were identified as würtzite-type ZnO (JCPDS 36-1451), with no observed impurity phases. In particular, the (002) peak was the strongest, indicating preferential crystal orientation along the $c$-axis. This orientation has often been observed in solution-processed ZnO. ${ }^{17,18}$ Cross-sectional and top-view SEM images of the asgrown and annealed N:ZnO NRAs are also shown in Fig. 1. Nearly vertically aligned N:ZnO NRAs were obtained on the FTO substrate; their morphologies were maintained during annealing at $500{ }^{\circ} \mathrm{C}$. The average diameter and length of the rods were approximately $210 \mathrm{~nm}$ and $12 \mu \mathrm{m}$, respectively.

Fig. 2 shows Raman spectra of the N:ZnO NRAs for the asgrown sample and for those annealed at different temperatures. All the spectra were normalized with respect to the highest peak intensity at $437 \mathrm{~cm}^{-1}$. This peak was observed for all samples, and was attributed to the characteristic vibration of the high-frequency $\mathrm{E}_{2}$ mode for würtzite-phase $\mathrm{ZnO} .{ }^{23}$ Peaks at $330 \mathrm{~cm}^{-1}$ were from multiple phonon scattering $\mathrm{E}_{2}(\mathrm{MP}){ }^{24}$

Additional peaks at $275 \mathrm{~cm}^{-1}, 510 \mathrm{~cm}^{-1}, 582 \mathrm{~cm}^{-1}, 635 \mathrm{~cm}^{-1}$ emerged after annealing above $400{ }^{\circ} \mathrm{C}$; they are usually attributed to N-related local vibrational modes in $\mathrm{ZnO} .^{16,25-27}$ According to calculations by Friedrich et al. ${ }^{24}$ the peak at $275 \mathrm{~cm}^{-1}$ may be assigned to a vibrational mode between zinc interstitials $\left(\mathrm{Zn}_{\mathrm{i}}\right)$ and the nitrogen substitution of oxygen $\left(\mathrm{N}_{\mathrm{O}}\right)$. It

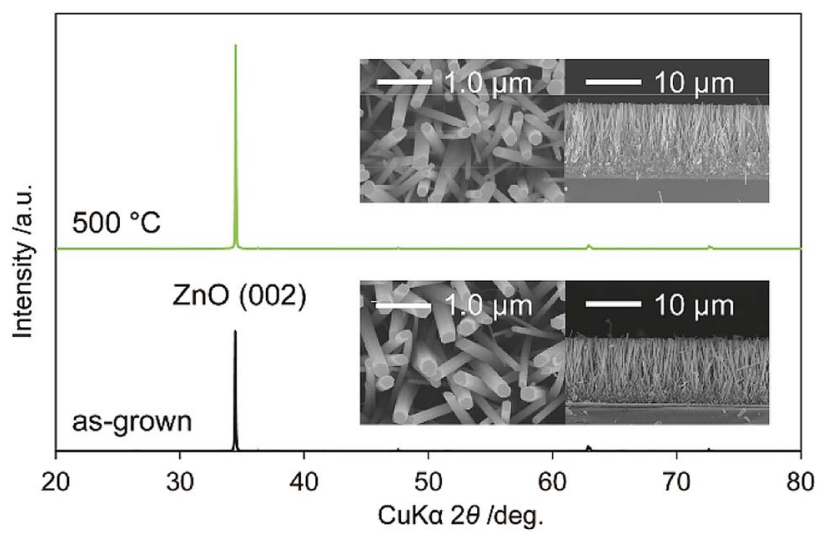

Fig. 1 XRD patterns of as-grown N:ZnO NRAs and those annealed at $500{ }^{\circ} \mathrm{C}$ for $1 \mathrm{~h}$. Cross-sectional and top-view SEM images are shown in the insets. 


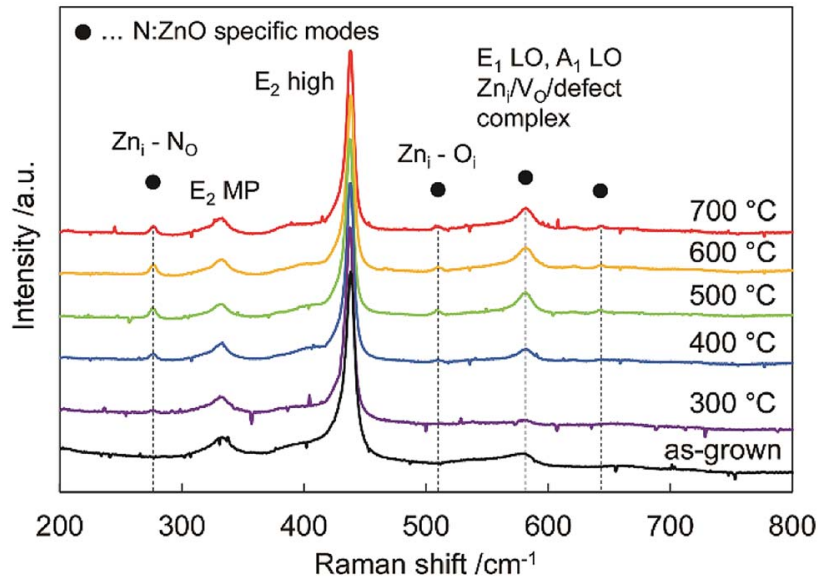

Fig. 2 Raman spectra of the as-grown $\mathrm{N}: \mathrm{ZnO} N R A$ and those annealed at $300-700{ }^{\circ} \mathrm{C}$ for $1 \mathrm{~h}$. All the spectra were normalized with respect to the peak intensity at $437 \mathrm{~cm}^{-1}$.

emerged after annealing above $400{ }^{\circ} \mathrm{C}$, and thus indicated that nitrogen was incorporated into the oxygen site. The peak at $581 \mathrm{~cm}^{-1}$ was assigned to an A1 longitudinal optical peak derived from defects such as an oxygen vacancy $(\mathrm{Vo}), \mathrm{Zn}_{\mathrm{i}}$, and defect complexes in $\mathrm{ZnO}^{28,29}$ It disappeared after annealing at $300{ }^{\circ} \mathrm{C}$, and appeared again after annealing above $400{ }^{\circ} \mathrm{C}$. This result indicates that crystallinity was improved by annealing at $300{ }^{\circ} \mathrm{C}$; whereas, new defects were created by nitrogen doping at annealing temperatures $>400^{\circ} \mathrm{C}$.

Fig. 3(a) shows the $275 \mathrm{~cm}^{-1}$ peaks in the Raman spectra fitted by Gaussian functions (dotted lines). Fig. 3(b) plots the calculated areas of the $275 \mathrm{~cm}^{-1}$ peaks $v s$. annealing temperature. The peak area increased with temperature, reached a maximum at around $500{ }^{\circ} \mathrm{C}$, and then decreased above $600{ }^{\circ} \mathrm{C}$. The peak intensity was a function of nitrogen dopant concentration. ${ }^{30,31}$ When annealing temperature $<400{ }^{\circ} \mathrm{C}, \mathrm{N}-\mathrm{H}$ bonds were not sufficiently broken; thus, N-related peaks were not observed. Temperatures above $400{ }^{\circ} \mathrm{C}$ were sufficient to rupture $\mathrm{N}-\mathrm{H}$ bonding. The nitrogen remained in the crystal, while the hydrogen eventually diffused out. ${ }^{32}$

To investigate sample defects, room-temperature PL spectroscopy was performed (Fig. 4). A strong near-band-edge luminescence at $380 \mathrm{~nm}$ is usually observed in $\mathrm{ZnO}^{33}$ but was suppressed and very weak in all the samples. This suggested that the samples had many defects, decreasing band-to-band transitions, and increasing band-to-defect level transitions or defect level-to-band transitions. The origin of the broad visible luminescence has been controversial because of its complexity. Generally, the violet emission originates from $\mathrm{Zn}_{\mathrm{i}}$-to-valence band transitions ${ }^{34}$ the yellow emission originates from $\mathrm{OH}$ groups made in the solution process, ${ }^{35}$ the orange emission originates from conduction band or $\mathrm{Zn}_{\mathrm{i}}$-to-oxygen interstitials $\left(\mathrm{O}_{\mathrm{i}}\right){ }^{36}$ and the red emission originates from the conduction band-to- $\mathrm{V}_{\mathrm{O}}$ or $\mathrm{V}_{\mathrm{O}}$-to-valence band transitions., ${ }^{37,38}$ Tarun et al. reported that the red emission originated from a nitrogen dopant state. ${ }^{39}$

In the as-grown sample, there were many $\mathrm{OH}$ group $/ \mathrm{V}_{\mathrm{O}}$ defects remaining in the crystal, thus there was yellow/red
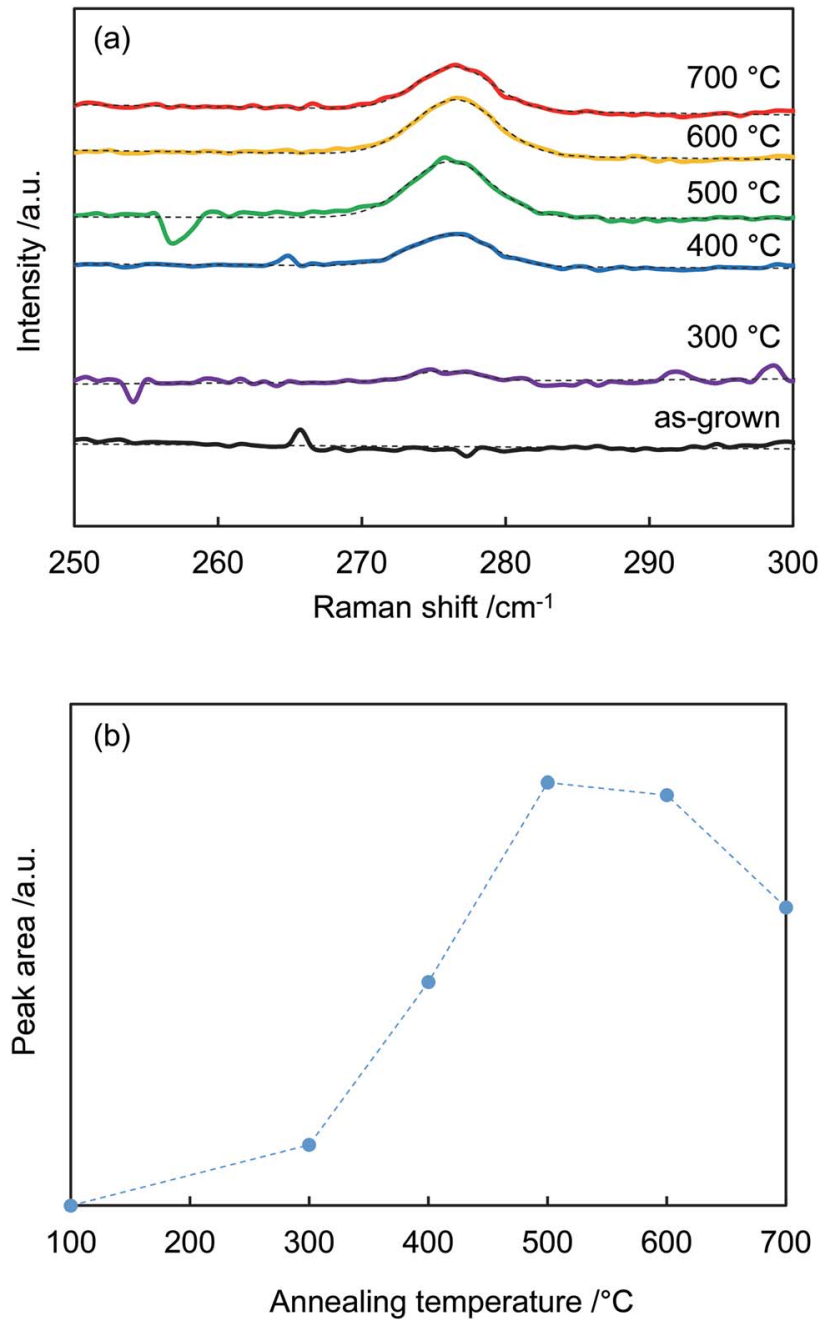

Fig. 3 (a) Raman spectra from Fig. 2 centered around $275 \mathrm{~cm}^{-1}$ and Gaussian fits. (b) Peak areas around $275 \mathrm{~cm}^{-1}$ vs. annealing temperature.

emission in the spectra. Annealing at $300{ }^{\circ} \mathrm{C}$ reduced the number of $\mathrm{OH}$ groups $/ \mathrm{V}_{\mathrm{O}}$ defects, decreasing the intensity of yellow/red luminescence. After $500{ }^{\circ} \mathrm{C}$ annealing, the $\mathrm{O}_{\mathrm{i}} / \mathrm{V}_{\mathrm{O}}$ defects increased because of $\mathrm{N}$ doping at oxygen sites,

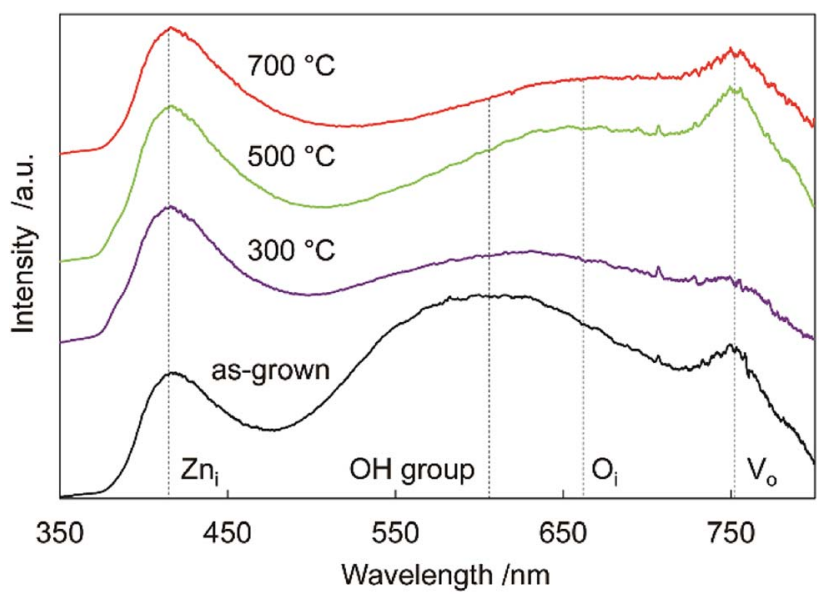

Fig. 4 Photoluminescence spectra of $\mathrm{N}: \mathrm{ZnO}$ NRAs after various annealing temperatures. 
increasing the orange/red luminescence. Annealing at $700{ }^{\circ} \mathrm{C}$ reduced all the defects in the crystal, and the total luminescence decreased. These results were supported by the Raman spectra (Fig. 2), which revealed the existence of $\mathrm{Zn}_{\mathrm{i}}, \mathrm{O}_{\mathrm{i}}$, and $\mathrm{V}_{\mathrm{O}}$ defects. Differential scanning calorimetry (DSC) measurement of the sample also suggested the reduction of oxygen vacancies and the decomposition of the incorporated ammonia. More detailed thermal analysis is under investigation.

Diffuse reflectance absorption spectra of the N:ZnO NRAs are shown in Fig. 5. Before annealing, the absorption edge shifted to longer wavelengths relative to that reported for $\mathrm{ZnO}(\sim 380$ $\mathrm{nm})$. This red shift was due to $\mathrm{V}_{\mathrm{O}}$ defect levels created by $\mathrm{NH}_{3}$ ligand incorporation, consistent with Raman and photoluminescence spectra (Fig. 2 and 4). Similar absorption shifts induced by oxygen vacancies have been previously reported and applied in visible-light-reactive photocatalysts. ${ }^{\text {40-42 }}$ After annealing at $300{ }^{\circ} \mathrm{C}$, the absorption edge shifted to shorter wavelengths, similar to that previously reported for $\mathrm{ZnO}$. Ambient annealing improved crystallinity and decreased the number of $\mathrm{V}_{\mathrm{O}}$ defects. Therefore, the absorption edge shift that had been caused by $\mathrm{V}_{\mathrm{O}}$ defects shifted back to the normal value
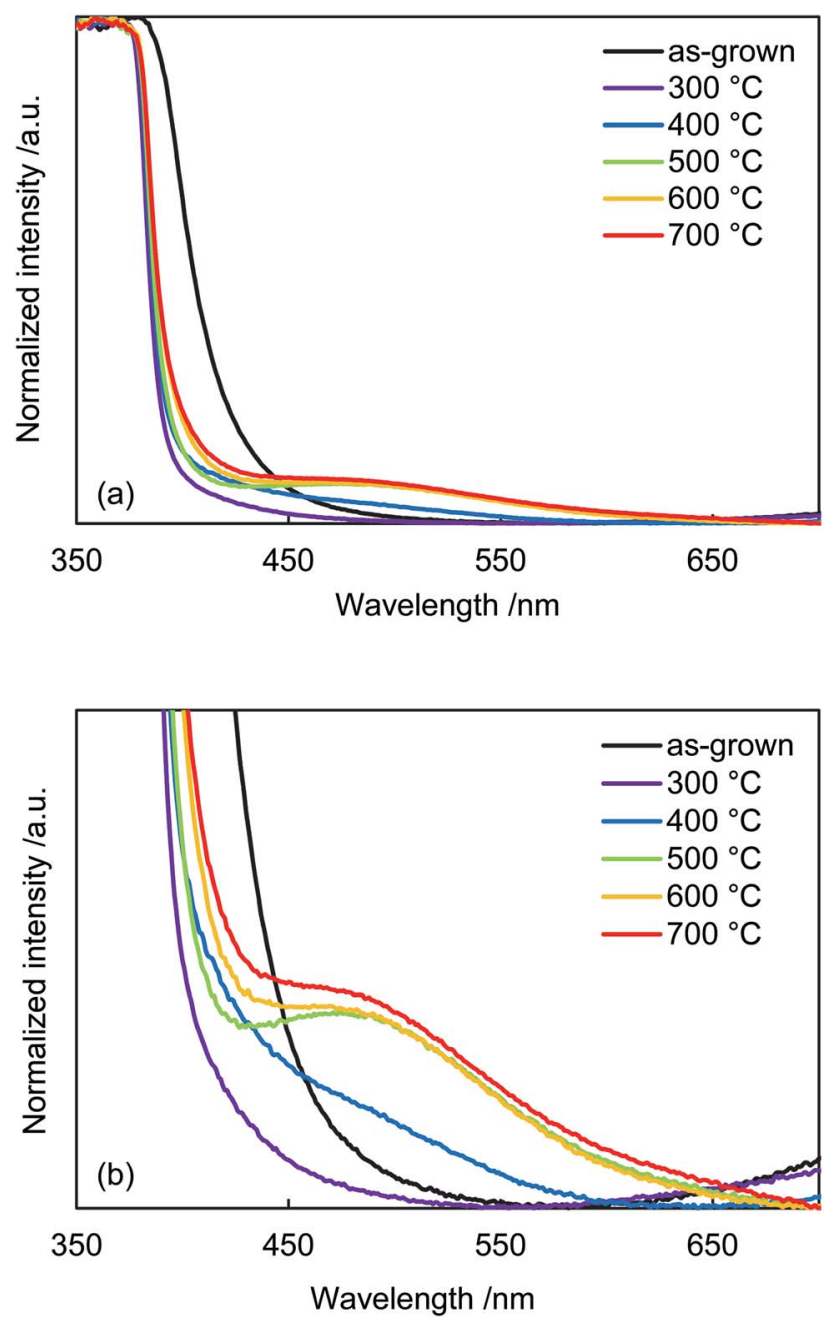

Fig. 5 (a) Diffuse-reflectance UV-vis spectra of as-grown $\mathrm{N}: \mathrm{ZnO}$ NRAs and those annealed at $300-700{ }^{\circ} \mathrm{C}$ for $1 \mathrm{~h}$. (b) Enlarged spectra from (a). for ZnO. After annealing at $>400{ }^{\circ} \mathrm{C}$, a broad shoulder absorption appeared around $500 \mathrm{~nm}$ that was attributed to the impurity levels formed by $\mathrm{N}$ doping. ${ }^{42}$ These changes in visible light absorption were consistent with color changes of the samples from pale-yellow (as-grown) to white (annealed at 300 ${ }^{\circ} \mathrm{C}$ ) and to pale orange (annealed $>500{ }^{\circ} \mathrm{C}$ ), as shown in Fig. S2. $\dagger$

XPS spectra of the $\mathrm{N} 1$ s core levels for the samples are shown in Fig. 6. All the $\mathrm{N}$ 1s spectra exhibited single broad peaks, and they were deconvoluted into two peaks centered at 398.9 and $399.8 \mathrm{eV}$. The peaks around $398.9 \mathrm{eV}$ were from nitrogen atoms in $\mathrm{NH}_{3},{ }^{42,43}$ and the peaks around $399.8 \mathrm{eV}$ were resulted from the formation of $\mathrm{O}-\mathrm{Zn}-\mathrm{N}$ bonds in the crystal. ${ }^{\mathbf{1 9 2 1 , 4 4}}$ The intensity of $\mathrm{O}-\mathrm{Zn}-\mathrm{N}$ related peak increased after annealing at $500{ }^{\circ} \mathrm{C}$. This result suggested that $\mathrm{N}$ was doped at the $\mathrm{O}$ sites in $\mathrm{ZnO}$ after $500{ }^{\circ} \mathrm{C}$ annealing, which strongly supports our discussion on nitrogen doping mechanism. Peak around $404 \mathrm{eV}$ was not observed in the spectra. This peak has been assigned to $\left(\mathrm{N}_{2}\right)_{\mathrm{O}},{ }^{45,46}$ thus the absence of the peak suggested the incorporated nitrogen was not from $\mathrm{N}_{2}$ molecule in the atmosphere, but from $\mathrm{NH}_{3}$ in the growth solution. The surface atomic ratio of $\mathrm{N}$ to $\mathrm{Zn}$ in the sample increased from $2.1 \%$ to $3.1 \%$ to $3.2 \%$ and to $4.7 \%$ in the as-grown sample and that annealed at $300{ }^{\circ} \mathrm{C}, 500{ }^{\circ} \mathrm{C}$ and $700{ }^{\circ} \mathrm{C}$. This result suggests that nitrogen was incorporated inside the crystal during the crystal growth, and it thermally diffused from inside to the surface during the annealing.

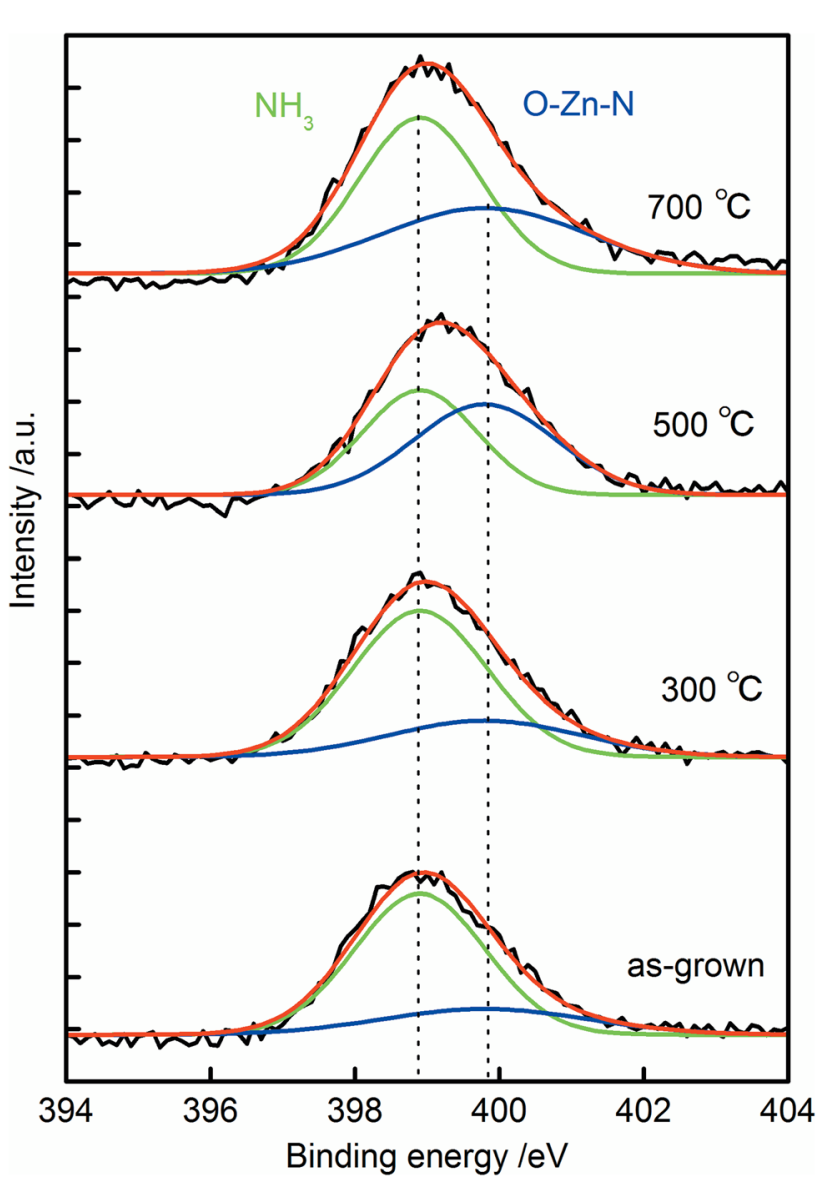

Fig. 6 XPS spectrum of the $\mathrm{N} 1 \mathrm{~s}$ region of as-grown $\mathrm{N}$ :ZnO NRAs and those annealed at $300-700{ }^{\circ} \mathrm{C}$ for $1 \mathrm{~h}$. 
Fig. 7 shows photocurrent $v s$. time $(I-t)$ measurements at $0.8 \mathrm{~V}$ recorded on $\mathrm{N}: \mathrm{ZnO}$ NRAs with light on/off cycles using $422 \mathrm{~nm}$ illumination. The data show a very low dark current of $<10^{-7} \mathrm{~A} \mathrm{~cm}^{-2}$. Upon illumination, an initial spike was observed in the photocurrent because of a power transient; the photocurrent then quickly relaxed to a steady-state value. The spikes were caused by photoexcited holes at electrode/electrolyte interfaces or at the interfaces within electrodes, which verified the existence of surface trap states in the sample. ${ }^{19}$ The maximum photocurrent occurred in the sample annealed at $500{ }^{\circ} \mathrm{C}$. This was over 18 times that for the as-grown sample, which exhibited very low photocurrent. The relationship between photocurrent density and annealing temperature correlated with the $275 \mathrm{~cm}^{-1}$ Raman peak intensities.

To determine the carrier density and the flat-band potential of the N:ZnO NRAs, Mott-Schottky analysis was performed using EIS. For flat electrodes, the Mott-Schottky equation is expressed by:

$$
\frac{1}{C^{2}}=\frac{2}{q N_{\mathrm{D}} \varepsilon_{\mathrm{ZnO}} \varepsilon_{0} A^{2}}\left(V-V_{\mathrm{fb}}\right)
$$

where $C$ is the capacitance, $q$ is the electron charge $\left(1.6 \times 10^{-19}\right.$ coulomb), $N_{\mathrm{D}}$ is the apparent donor density, $\varepsilon_{\mathrm{ZnO}}$ is the dielectric constant of $\mathrm{ZnO}(10),{ }^{47} \varepsilon_{\mathrm{o}}$ is the permittivity of free space $\left(8.85 \times 10^{-14}\right.$ farad-cm $\left.{ }^{-1}\right), A$ is the active electrode surface area, $V$ is the applied voltage, and $V_{\mathrm{fb}}$ is the flat-band potential. The capacitance $C$ was calculated by fitting the spectra with the equivalent circuit of the photoanode, which was $L_{\mathrm{S}}+R_{\mathrm{S}}+\left(R_{\mathrm{H}} / /\right.$ $\left.\mathrm{CPE}_{\mathrm{H}}\right)+\left(R_{\mathrm{sc}} / / \mathrm{CPE}_{\mathrm{sc}}\right)$. Here, $L_{\mathrm{S}} / R_{\mathrm{S}}$ was the inductance/resistance in the electrolyte or electrical contact. The parallel circuit of resistance $R_{\mathrm{H}}$ and the constant phase element $\mathrm{CPE}_{\mathrm{H}}$ represented the Helmholtz layer at the $\mathrm{ZnO}$ /electrolyte interface, and the parallel circuit of $R_{\mathrm{sc}}$ and $\mathrm{CPE}_{\mathrm{sc}}$ represented the spacecharge layer at the $\mathrm{ZnO} /$ electrolyte interface. Usually, the capacitance in a space-charge layer is much smaller than that in a Helmholtz layer, therefore that in the Helmholtz layer can be neglected in a Mott-Schottky plot.

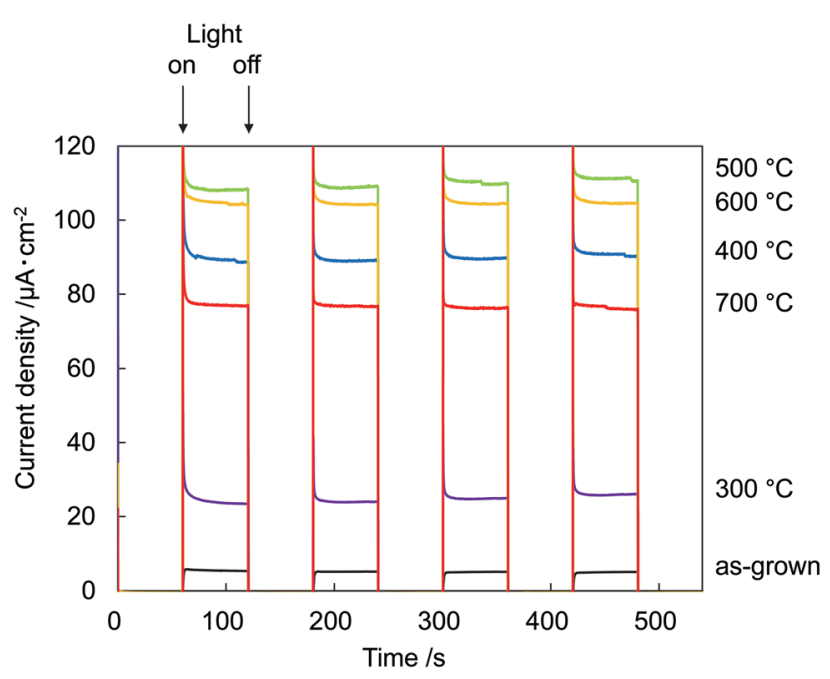

Fig. 7 Electrochemical $1-t$ measurements recorded on $\mathrm{N}: Z n O$ NRAs with light on/off cycles at $0.8 \mathrm{~V}$ using $>422 \mathrm{~nm}$ illumination.
The impedance of the constant-phase element $Z_{\mathrm{CPE}}$ was:

$$
Z_{\mathrm{CPE}}=\frac{1}{(\mathrm{j} \omega)^{p} T}
$$

where $T$ was the CPE prefactor, $\omega$ was the angular frequency $(2 \pi f), p$ was $0 \leq p \leq 1$, and $\mathrm{j}$ was an imaginary number. The value of $C$ could be determined directly from $T$ when $p=1$. Here, $p$ was almost constant over the entire voltage range in the space-charge layer area, and average values for each sample were $>0.9$. Therefore, assuming that the electrode capacitance could be represented directly by $T$, the Mott-Schottky plot was constructed using $T$ instead of $C$.

In Fig. 8 is plotted $C^{-2}$ vs. $V$. The positive slopes suggested that all the $\mathrm{N}$ :ZnO NRAs were n-type semiconductors, despite the nitrogen doping. There were two main reasons for $n-$ type $\mathrm{N}: \mathrm{ZnO}$ in this experiment. First, there were a lot of compensating donor defects in the sample. According to the Raman and PL spectra (Fig. 2 and 4), the existence of $Z_{i}$ and $V_{O}$ were suggested. These defects worked as electron donor and compensated the acceptor-nitrogen in the crystal. Second, the acceptor-nitrogen concentration was too low to turn n-type to ptype. The Raman peak intensities at $275 \mathrm{~cm}^{-1}$ (shown in Fig. 2) were weaker than those shown in the previous reports on $\mathrm{p}$ type N:ZnO. ${ }^{21,27}$ This peak is assigned to a vibrational mode between $\mathrm{Zn}_{\mathrm{i}}$ and $\mathrm{N}_{\mathrm{O}}$, and thus it represents the amount of nitrogen in the crystal. The weak intensity of the peak insists low nitrogen concentration in the sample. To determine the apparent donor density $N_{\mathrm{D}}$ from the Mott-Schottky analysis, the active surface area was estimated. N:ZnO NRAs were deposited on a $4 \mathrm{~cm}^{2}$ area, but the actual active surface area was much larger because of the side areas of the rod arrays. From the SEM image in Fig. 1, the actual surface area could be estimated from the rod lengths, diameters, and density. There were about $25 \times$ $10^{6}$ nanowires per $\mathrm{cm}^{2}$, with an average radius $r=210 \mathrm{~nm}$ and an average length $h=12 \mu \mathrm{m}$. Assuming a cylindrical surface area $\left(A_{\text {cylinder }}=2 \pi r^{2}+2 \pi r h\right)$, a total active surface area of $A=$ $16.1 \mathrm{~cm}^{2}$ was determined.

The calculated donor densities and flat band potentials are listed in Table 1 . A low carrier density was calculated for the as-

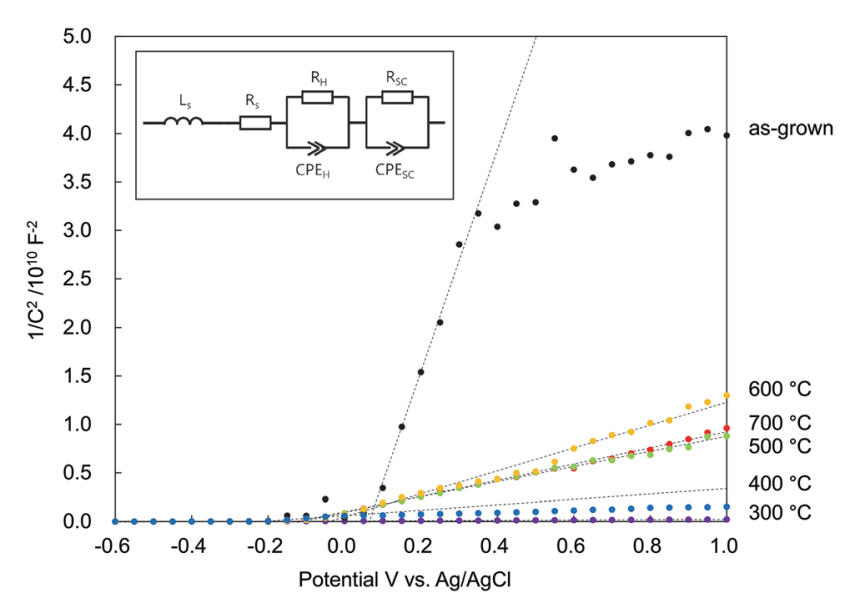

Fig. 8 Mott-Schottky plots of N:ZnO NRAs under dark conditions as a function of various annealing temperatures (inset: equivalent circuit of the photoanode used for the calculations). 
Table 1 Calculated carrier densities and flat-band potentials from eqn (1) for N:ZnO NRAs after different annealing temperatures. A cylindrical approximation was used for estimating the surface area of $\mathrm{N}: \mathrm{ZnO}$ NRAs

\begin{tabular}{|c|c|c|}
\hline Sample & Carrier density $/ \mathrm{cm}^{-3}$ & $\begin{array}{l}\text { Flat band potential/ } \\
\mathrm{V} v s . \mathrm{Ag} / \mathrm{AgCl}\end{array}$ \\
\hline As-grown & $4.76 \times 10^{17}$ & 0.065 \\
\hline $300{ }^{\circ} \mathrm{C}$ & $3.16 \times 10^{20}$ & -0.293 \\
\hline $400{ }^{\circ} \mathrm{C}$ & $1.96 \times 10^{19}$ & -0.218 \\
\hline $500{ }^{\circ} \mathrm{C}$ & $7.00 \times 10^{18}$ & -0.128 \\
\hline $600{ }^{\circ} \mathrm{C}$ & $4.61 \times 10^{18}$ & -0.041 \\
\hline $700{ }^{\circ} \mathrm{C}$ & $6.55 \times 10^{18}$ & -0.110 \\
\hline
\end{tabular}

grown sample because there were many defects revealed in the PL spectra. After annealing at $300{ }^{\circ} \mathrm{C}$, the defect density was reduced and trapped electrons were released; thus, the donor density increased sharply. However, the donor density decreased after annealing above $500{ }^{\circ} \mathrm{C}$, indicating that doped nitrogen acted as an accepter in the $\mathrm{ZnO}$. The donor density continuously decreased up to $600{ }^{\circ} \mathrm{C}$ and then increased again with annealing at $700{ }^{\circ} \mathrm{C}$. This implied that the nitrogen accepter diminished at higher temperatures. The flat band potential was negatively shifted after annealing at $300{ }^{\circ} \mathrm{C}$, and then positively shifted after annealing at $500{ }^{\circ} \mathrm{C}$. These results indicated that electrons were released and that the Fermi level rose after $300{ }^{\circ} \mathrm{C}$ annealing, and then the doped nitrogen and the Fermi level fell again after $>500{ }^{\circ} \mathrm{C}$ annealing.

\section{Conclusion}

$\mathrm{N}$ :ZnO NRAs were fabricated by hydrothermal synthesis using a zinc-ammine complex solution, followed by post-annealing at various temperatures under ambient conditions. Raman and photoluminescence spectra indicated that post-annealing dissociated the $\mathrm{NH}_{3}$-ligands, allowing nitrogen to be incorporated at oxygen sites. When annealing occurred at a sufficiently high temperature, weak absorption appeared in the visible region ( $\sim 500 \mathrm{~nm})$. The $\mathrm{N}: \mathrm{ZnO}$ NRAs generated strong visiblelight-induced (>422 nm) photocurrents after post-annealing. This procedure requires neither expensive nor complex equipment, and thus should be applicable for large-scale fabrication of N:ZnO NRAs.

\section{Conflicts of interest}

There are no conflicts to declare.

\section{Acknowledgements}

This work was supported by MEXT Nanotechnology platform 12025014(F-17-IT-0017) for the micro structure images of samples. A part of this work was financially supported by Research Grant, The Murata Science Foundation. We thank Alan Burns, PhD, from the Edanz Group (https:// www.edanzediting.com/ac) for editing a draft of this manuscript.

\section{References}

1 S. Liang, H. Sheng, Y. Liu, Z. Huo, Y. Lu and H. Shen, J. Cryst. Growth, 2001, 225, 110-113.

2 J. Xu, Q. Pan and Z. Tian, Sens. Actuators, B, 2000, 66, 277279.

3 X. Jiang, F. Wong, M. Fung and S. Lee, Appl. Phys. Lett., 2003, 83, 1875-1877.

4 M. H. Huang, S. Mao, H. Feick, H. Yan, Y. Wu, H. Kind, E. Weber, R. Russo and P. Yang, Science, 2001, 292, 18971899.

5 J. B. Baxter and E. S. Aydil, Appl. Phys. Lett., 2005, 86, 053114. 6 X. M. Zhang, M. Y. Lu, Y. Zhang, L. J. Chen and Z. L. Wang, Adv. Mater., 2009, 21, 2767-2770.

7 S.-J. Young, C.-C. Yang and L.-T. Lai, J. Electrochem. Soc., 2017, 164, B3013-B3028.

8 C.-L. Hsu, Y.-H. Lin, L.-K. Wang, T.-J. Hsueh, S.-P. Chang and S.-J. Chang, ACS Appl. Mater. Interfaces, 2017, 9, 1493514944.

9 T. Chen, S. Young, S. Chang, C. Hsiao and C. Huang, J. Electrochem. Soc., 2012, 159, J153-J157.

10 L.-W. Ji, C.-Z. Wu, C.-M. Lin, T.-H. Meen, K.-T. Lam, S.-M. Peng, S.-J. Young and C.-H. Liu, Jpn. J. Appl. Phys., 2010, 49, 052201.

11 A. Wolcott, W. A. Smith, T. R. Kuykendall, Y. Zhao and J. Z. Zhang, Adv. Funct. Mater., 2009, 19, 1849-1856.

12 H. M. Chen, C. K. Chen, Y. C. Chang, C. W. Tsai, R. S. Liu, S. F. Hu, W. S. Chang and K. H. Chen, Angew. Chem., 2010, 122, 6102-6105.

13 D. Li and H. Haneda, J. Photochem. Photobiol., A, 2003, 155, 171-178.

14 X. Yang, A. Wolcott, G. Wang, A. Sobo, R. C. Fitzmorris, F. Qian, J. Z. Zhang and Y. Li, Nano Lett., 2009, 9, 2331-2336.

15 B. Xiang, P. Wang, X. Zhang, S. A. Dayeh, D. P. Aplin, C. Soci, D. Yu and D. Wang, Nano Lett., 2007, 7, 323-328.

16 B. Yang, P. Feng, A. Kumar, R. Katiyar and M. Achermann, J. Phys. D: Appl. Phys., 2009, 42, 195402.

17 M. Guo, P. Diao and S. Cai, J. Solid State Chem., 2005, 178, 1864-1873.

18 A. Sugunan, H. C. Warad, M. Boman and J. Dutta, J. Sol-Gel Sci. Technol., 2006, 39, 49-56.

19 M. Wang, F. Ren, J. Zhou, G. Cai, L. Cai, Y. Hu, D. Wang, Y. Liu, L. Guo and S. Shen, Sci. Rep., 2015, 5, 12925.

20 R. G. Palgrave, D. J. Payne and R. G. Egdell, J. Mater. Chem., 2009, 19, 8418-8425.

21 B. Chavillon, L. Cario, A. Renaud, F. Tessier, F. Cheviré, M. Boujtita, Y. Pellegrin, E. Blart, A. Smeigh and L. Hammarstrom, J. Am. Chem. Soc., 2011, 134, 464-470.

22 S. Meyers, J. Anderson, C. Hung, J. Thompson, J. Wager and D. Keszler, J. Am. Chem. Soc., 2008, 130, 17603-17609.

23 T. C. Damen, S. Porto and B. Tell, Phys. Rev., 1966, 142, 570. 24 F. Friedrich, M. Gluba and N. Nickel, Appl. Phys. Lett., 2009, 95, 141903.

25 A. Kaschner, U. Haboeck, M. Strassburg, M. Strassburg, G. Kaczmarczyk, A. Hoffmann, C. Thomsen, A. Zeuner, 
H. Alves and D. Hofmann, Appl. Phys. Lett., 2002, 80, 19091911.

26 L. L. Kerr, X. Li, M. Canepa and A. J. Sommer, Thin Solid Films, 2007, 515, 5282-5286.

27 N. P. Herring, L. S. Panchakarla and M. S. El-Shall, Langmuir, 2014, 30, 2230-2240.

28 G. J. Exarhos and S. K. Sharma, Thin Solid Films, 1995, 270, 27-32.

29 C. Youn, T. Jeong, M. Han and J. Kim, J. Cryst. Growth, 2004, 261, 526-532.

30 J. Sann, J. Stehr, A. Hofstaetter, D. Hofmann, A. Neumann, M. Lerch, U. Haboeck, A. Hoffmann and C. Thomsen, Phys. Rev. B: Condens. Matter Mater. Phys., 2007, 76, 195203.

31 K. Jindal, M. Tomar, R. Katiyar and V. Gupta, J. Appl. Phys., 2016, 120, 135305.

32 J. Gao, X. Zhang, Y. Sun, Q. Zhao and D. Yu, Nanotechnology, 2010, 21, 245703.

33 B. Meyer, H. Alves, D. Hofmann, W. Kriegseis, D. Forster, F. Bertram, J. Christen, A. Hoffmann, M. Straßburg and M. Dworzak, Phys. Status Solidi B, 2004, 241, 231-260.

34 C. H. Ahn, Y. Y. Kim, D. C. Kim, S. K. Mohanta and H. K. Cho, J. Appl. Phys., 2009, 105, 013502.

35 A. Djurišić, Y. Leung, K. Tam, Y. Hsu, L. Ding, W. Ge, Y. Zhong, K. Wong, W. Chan and H. Tam, Nanotechnology, 2007, 18, 095702.
36 X. Liu, X. Wu, H. Cao and R. Chang, J. Appl. Phys., 2004, 95, 3141-3147.

37 N. Alvi, K. Ul Hasan, O. Nur and M. Willander, Nanoscale Res. Lett., 2011, 6, 130.

38 F. Stavale, L. Pascua, N. Nilius and H.-J. Freund, J. Phys. Chem. C, 2014, 118, 13693-13696.

39 M. Tarun, M. Z. Iqbal and M. McCluskey, AIP Adv., 2011, 1, 022105.

40 J. Wang, Z. Wang, B. Huang, Y. Ma, Y. Liu, X. Qin, X. Zhang and Y. Dai, ACS Appl. Mater. Interfaces, 2012, 4, 4024-4030.

41 H.-L. Guo, Q. Zhu, X.-L. Wu, Y.-F. Jiang, X. Xie and A.-W. Xu, Nanoscale, 2015, 7, 7216-7223.

42 X. Zong, C. Sun, H. Yu, Z. G. Chen, Z. Xing, D. Ye, G. Q. Lu, X. Li and L. Wang, J. Phys. Chem. C, 2013, 117, 4937-4942.

43 X. Wang, J. C. Yu, Y. Chen, L. Wu and X. Fu, Environ. Sci. Technol., 2006, 40, 2369-2374.

44 L.-C. Chen, Y.-J. Tu, Y.-S. Wang, R.-S. Kan and C.-M. Huang, J. Photochem. Photobiol., A, 2008, 199, 170-178.

45 K. Ahn, Y. Yan, S. Lee, T. Deutsch, J. Turner, C. Tracy, C. Perkins and M. Al-Jassim, J. Electrochem. Soc., 2007, 154, B956-B959.

46 C. Perkins, S. Lee, X. Li, S. Asher and T. Coutts, J. Appl. Phys., 2005, 97, 034907.

47 I. Mora-Seró, F. Fabregat-Santiago, B. Denier, J. Bisquert, R. Tena-Zaera, J. Elias and C. Lévy-Clément, Appl. Phys. Lett., 2006, 89, 203117. 